\section{Offshore outsourcing of R\&D to emerging markets: information systems as tools of neo-colonial control}

Outsourcing of R\&D to emerging markets

281

\author{
Zehra Sayed
}

Gothenburg Research Institute, School of Business, Economics and Law, University of Gothenburg, Gothenburg, Sweden, and

Henrik Agndal

Department of Business Administration, School of Business, Economics and Law, University of Gothenburg, Gothenburg, Sweden

\begin{abstract}
Purpose - This paper analyzes how information systems (IS) can serve as tools of neo-colonial control in offshore outsourcing of research and development work. It draws on critical work examining business and knowledge process outsourcing.

Design/methodology/approach - The paper reports an empirical study of how laboratory information management systems (LIMS) shape offshore outsourcing practices involving Western client firms and Indian contract research organizations (CROs) in the pharmaceutical industry. The study adopted a multi-actor perspective, involving interviews with representatives of Western clients, Indian CROs, system validation auditors, and software vendors. The analysis was iterative and interpretative, guided by postcolonial sensitivity to themes of power and control.

Findings - The study found that LIMS act as tools of neo-colonial control at three levels. As Western clients specify particular brands of LIMS, they create a hierarchy among local CROs and impact the development of the local LIMS industry. At inter-organizational level, LIMS shape relationships by allowing remote, real-time and retrospective surveillance of CROs' work. At individual level, the ability of LIMS to support micro-modularizing of research leads to routinization of scientific discovery, negatively impacting scientists' work satisfaction.

Originality/value - By examining multiple actors' perceptions of IS, this paper looks beyond the rhetoric of system efficiency characteristic of most international business research. As it explores dynamics of power and control surrounding IS, it also questions the proposition that outsourcing of high-end work will move emerging economies upstream in the value chain.
\end{abstract}

Keywords Offshoring, Pharmaceutical industry, Outsourcing, Information systems, Neo-colonial, Postcolonial theory, IS

Paper type Research paper

\section{Introduction}

Offshore outsourcing to emerging markets is no longer restricted to low-end activities. In recent years, offshore outsourcing has come to include an array of knowledge-intensive

(C) Zehra Sayed and Henrik Agndal. Published by Emerald Publishing Limited. This article is published under the Creative Commons Attribution (CC BY 4.0) licence. Anyone may reproduce, distribute, translate and create derivative works of this article (for both commercial and non-commercial purposes), subject to full attribution to the original publication and authors. The full terms of this licence may be seen at http://creativecommons.org/licences/by/4.0/legalcode

Torsten Soderbergs Stiftelse. The authors gratefully acknowledge funding provided by Handelsbankens Forskningsstiftelser and Torsten Soderbergs Stiftelse.
Received 5 July 2020 Revised 20 January 2021 31 March 2021 Accepted 14 April 2021

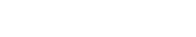


CPOIB 18,3

functions that are critical to firms' success (UNCTAD, 2005; Sartor and Beamish, 2014; Papanastassiou et al., 2020), often high-end activities previously considered too complex and risky to outsource. This development has been made possible in part by advancements in information systems (IS), enabling remote real-time monitoring of contracts (Aron et al., 2008; Aneesh, 2009). Such tools not only allow client firms to specify and supervise output but also to oversee a vendor as it executes its tasks, exercising managerial control as though it were operating in a hierarchical setting. With such information-management tools, a client firm can thus take full advantage of wage arbitrage while simultaneously managing vendors' potential post-contractual opportunistic behaviour. As a result, firms are less hesitant to outsource high-end activities like research and development (R\&D) to emerging markets such as India and China (Aron et al., 2008).

Postcolonial studies of international business have critically extended our understanding of the ways in which the offshore outsourcing phenomenon is shaped by neo-colonial power relations, reflecting the enduring legacy of colonialism in contemporary global economic relationships (Cohen and El-Sawad, 2007; Mir et al., 2008; Zimmermann, 2011). Studies have demonstrated in particular how historically derived power asymmetries are reflected in the ways in which vendors from the Global South function, experience and respond to outsourcing work they undertake for Western clients (Mir and Mir, 2009; Ravishankar et al., 2013). Critical work has also engaged with the role of information and communication technology (ICT) in bolstering neo-colonial exploitation, particularly in the context of lowend business process outsourcing such as call centres (Mirchandani, 2005, 2012; Nadeem, 2009; Poster, 2011). There is significant room, however, to extend these contributions by exploring how IS enforce imperialist ideologies and buttress offshoring as a neo-colonial endeavour in outsourcing of high-end functions. In particular, there is scope to expand our knowledge of how IS shape client-vendor relationships and production networks in the context of knowledge-process outsourcing. This is an especially critical line of inquiry given that R\&D outsourcing is often posited as a development that helps emerging markets move upstream along the value chain and enables their firms to acquire more equitable roles in global production networks (Fernandez-Stark et al., 2011).

Our central research question is, therefore, how do IS serve as tools of neo-colonial control in offshore outsourcing of $R \& D$ work? To address this question, we conducted an empirical inquiry of offshore outsourcing of pharmaceutical R\&D to contract research organizations (CROs) in India, particularly emphasizing the role of laboratory information management systems (LIMS) in shaping outsourcer-outsource relations. While some critical work has examined outsourcing of clinical drug trials to the Global South (Nundy and Gulhati, 2005; SunderRajan, 2006; Petryna, 2009), we looked specifically at the discovery phase of drug development, an area that has apparently been left largely unexplored by critical studies.

In the following section, we draw on insights from postcolonial work on offshore outsourcing as a basis for understanding how neo-colonial control is exercised in businessprocess and knowledge-process outsourcing and engage with critical discussions of IS. We subsequently describe how we performed data collection and analysis. In the next section, we provide a brief description of the research context. We then present our findings regarding how IS - in various ways and at various levels - act as tools of neo-colonial control in the global pharmaceutical drug-development network. We then discuss these findings and address the limitations of our study.

\section{Review of critical literature on technology and outsourcing}

In spite of the obvious centrality of IS to offshoring, mainstream international business research has obstinately neglected the inherent potential of information tools to perpetuate 
power imbalances, instead of treating IS purely as tools of business performativity and efficiency (Irani and Dourish, 2009; Alcaraz et al., 2012). This taken-for-grantedness is symptomatic of how the use of software and other digitally-enabled informationmanagement systems are defined strictly in terms of their applications. It is also symptomatic of how the choice of software and its effects on work processes are largely ignored in mainstream studies. Critical research across academic subfields such as critical software studies, critical code studies, postcolonial computing and science and technology studies have, however, challenged the essentialist/functionalist view of IS as value-free and inherently liberatory (Mitev, 2006; Phillip et al., 2016). Through postcolonial theoretical lenses, research in this vein has shown how the design, operation and application of IS is embedded within enduring historical relationships between the West and the global rest.

\section{Neo-colonialism and business-process offshore outsourcing}

The call-centre industry - the most prototypical example of business-process outsourcing has been a prominent focal point of critical discussions of offshore outsourcing since its early beginnings. Initially, public debate in the Global North revolved around fears of job loss. Subsequently, scholarly attention pointed to call-centre offshoring as a manifestation of neo-colonial control, understanding its novel forms of exploitation as colonial legacies of capitalism (Taylor and Bain, 2005; Mirchandani, 2004, 2007; Poster, 2007; Basi, 2009). In this vein, critics argue that offshoring driven by cost considerations and, particularly, labour arbitrage allows for only new iterations of extant international divisions of labour founded on core-and-periphery hierarchies (Mir and Mir, 2009; Boussebaa and Morgan, 2014). As the Global North extracts value produced by the Global South, the lives of workers in outsourcing host economies are continuously cheapened as these workers do not hold positions that allow them to accumulate any of the surplus value they produce (Banerjee, 2008; Vora, 2013). The transnational nature of offshoring thus leads to the accumulation of value outside the worker community, resulting in net flows of affective resources to consuming nations at the expense of producing nations. Some studies have pointed to the key role played by local elites - a "comprador" class of firms - in buttressing the interests of global elite firms in offshore markets (Boussebaa and Morgan, 2014). By acting as intermediaries in the extraction of capital from host environments, compradors not only constitute a central component in the expansion of global production networks but also represent organizations whose very existence is premised on that expansion.

Technology is a resonant trope in much of the academic debate on offshoring, where it is understood both as an enabler of work relocation to distant shores and a monitoring tool for client firms from the Global North (Poster, 2007, 2011). These discussions centre on the informating capability of technology (Zuboff, 1988), particularly the capacity of an IS to automate organizational routines while simultaneously generating "electronic text" about underlying productive and administrative work processes, making these visible. To understand offshoring of technology-mediated work such as call-centre operations, we, therefore, must recognize how they are configured by information-system capabilities to provide real-time surveillance independent of worker location. In this vein, a significant number of studies have shown how informating technologies such as dialling software and automated call distribution systems are used to increase call-centre productivity by enabling employee performance assessment (Taylor and Bain, 2005; Russell, 2007; Basi, 2009) and by allowing international clients to maintain close control over the quality of work performed by service providers (Batt et al., 2006; Taylor and Bain, 2001; Bain et al., 2002).

Scholars have described such work settings as electronic panopticons (Fernie and Metcalf, 1998), electronic sweatshops (Garson, 1988) and panoptical wired cages 
CPOIB 18,3

(Menzies, 1996), configurations that objectify workers and, in many cases, result in total domination of labouring subjects. Empirical work points out how these surveillance technologies create stressful work environments where workers must constantly protect who they are; while projecting false identities to satisfy Western customers (Mirchandani, 2004), they must keep up with the pace of the dialling system to satisfy criteria enforced through constant monitoring of their behaviour (Russell, 2008; Valle et al., 2012). Studies also draw attention to how these IT systems enable simplification and rigid standardization of outsourced work, rendering it of low value, routinized, repetitive and non-innovative in nature (Batt et al., 2006; Budhwar et al., 2006; Ofreneo et al., 2007). Study findings indicate that such work offers limited scope for employee empowerment and skill development, particularly as the skills specific to the call-centre industry are rarely valued outside this sector (Noronha and D'Cruz, 2006).

It would, however, be simplistic to project the debate on call-centre work only in terms of technological determinism. Several studies have noted covert and creative ways in which workers resist technological control (Taylor and Bain, 1999; Bain and Taylor, 2000; Callaghan and Thompson, 2001; Lankshear et al., 2001), challenging the influential assumption that the informating capabilities of information technologies will elicit their intended self-discipline among workers. This line of thinking notwithstanding, scholarship on call-centre offshoring has so far largely emphasized control over resistance, as acts of resistance are often surreptitious and may have only symbolic effects. The mere presence of resistance, however, introduces disruption to the narrative of technological power.

\section{Neo-colonialism and knowledge-process offshore outsourcing}

Critical work has also explored the neo-colonial implications of the outsourcing of knowledge processes such as R\&D, particularly the outsourcing of clinical trials to the Global South (Nundy and Gulhati, 2005; SunderRajan, 2006; Petryna, 2009). The general argument is that this represents a new form of colonialism in which impoverished trial subjects are systematically exploited for the benefit of pharmaceutical companies and people of the Global North (Sariola et al., 2015). Central to such discussions is the concern that clinical trials performed in countries such as India are largely irrelevant to the health needs of the vast majority of local populations (Prasad, 2009). Critics have also pointed out that the outsourcing of clinical trials to developing nations is expanding as regulatory regimes are making it increasingly difficult and legally risky to conduct trials in the Global North. In comparison, places such as India provide pharmaceutical firms with a more relaxed regulatory environment while simultaneously offering lower labour costs, including costs for physicians, nurses, study coordinators and, not least, trial participants (Glickman et al., 2009). Many pharmaceutical outsourcing enthusiasts have pointed to "spillover" benefits of clinical trials, such as business opportunities bolstering local biotechnology research (Prasad, 2009). Critics, however, have contended that cheap production of trial data and access to large locals markets for global pharmaceutical firms are more salient outcomes of outsourcing than the development of local biotech knowledge (Kamat, 2014). Other than studies of pharmaceutical offshore outsourcing, we find some critical work that analyzes the neo-colonial implications of information technology (IT) offshore outsourcing (Mayasandra et al., 2006; Ravishankar et al., 2013; Phillip, 2016), uncovering the power asymmetries in client-vendor relationships. Vora's (2013) extensive work on outsourcing reveals, in particular, that IT work that tends to get outsourced comprises mostly repetitive, technical, customer-service-oriented tasks.

From extant work, we can conclude that offshore outsourcing has greatly increased the ability of Western firms to extract value from ever greater numbers of regions and peoples 
across the globe. In this endeavour, IS are a key ally, assisting in the production, organization and management of new contexts as sites of wealth accumulation. While critical work on-call centres has engaged with the enabling role of technologies involved in offshoring of low-end work and its neo-colonial implications, a similar engagement with high-end work is warranted, not least given the increase in outsourcing of knowledgeintensive functions. As we pursue research in the context of the outsourcing of pharmaceutical drug development, we strive to address how neo-colonial power is exercised through IS. We ask: how is the ethical discourse on pharmaceutical research used to justify the implementation of information-system tools that support the extraction of value? How do clients and other actors in the global production network draw on this discourse to convince third parties such as CROs to place client interests at the centre and act against their own interests? In other words, how does the ethical rhetoric of drug development mask the dynamics of IS, seemingly rendering them apolitical and objective?

\section{Research context: offshore outsourcing of pharmaceutical drug development to India}

The outsourcing of R\&D has become a strategic imperative for most leading pharmaceutical firms from the Global North (Subramaniam and Dugar, 2012). Third-party providers such as CROs in emerging markets are increasingly the recipients of such externalized R\&D work (Adobor, 2012). CROs typically specialize in one or more drug discovery or development phases, providing R\&D services on a contract basis (Mirowski and Van Horn, 2005). CROs thereby enable client firms to increase capital efficiency by shifting fixed costs to variable costs, as well as address capacity shortfalls and gaps in internal expertise and capabilities, allowing outsourcers to focus on core competencies. Given these advantages, the outsourcing trend for drug discovery is predicted to grow by $5 \%$ to $10 \%$ annually over the next decade (Steadman, 2018).

\section{The contract research organization industry in India}

India is a leading outsourcing destination for big pharmaceutical firms (Kamat, 2014), with the Indian CRO industry reaching a market valuation of US\$1bn in 2017 with a projected annual growth rate of $12 \%$ over the period running from 2017 to 2023 (www. marketresearchfuture.com). While the precise number of CROs is difficult to establish given the large numbers of new entrants, joint ventures and mergers and acquisitions (Differding, 2014), Kamat (2014) estimated the number at around 150. Of these, approximately 40 to 50 are able to compete for international contracts while the remaining CROs work primarily with domestic clients (personal communication with an industry distributor).

The emergence of the Indian CRO industry can be explained in part by changes in patent legislation undertaken in connection with India's joining the WTO in 2005. Previously, the 1970 Patent Act granted only process patents, allowing for reverse-engineering of drugs and leading to the establishment of a large manufacturing base for generic drugs serving both domestic and export markets (Rao, 2008). The 2005 revised patent legislation, however, offered protection for both product and process rights, effectively opening the market to big Western pharmaceutical firms and the outsourcing of clinical trials and drug development (Kamat, 2014). Simultaneously, the development of domestic drug manufacturing ensured the ready availability of skilled labour, including lab workers, physicians, nurses and study coordinators who could - and continue to - be recruited for much lower wages than their counterparts in the West (Glickman et al., 2009). 
CPOIB

18,3

286

\section{Laboratory information-management systems}

The automation of laboratory processes is becoming progressively more important in the pharmaceutical industry. Recent advances in IT have enabled automation hardware increasingly to be complemented by intelligent software that integrates physical experimentation with the formulation of hypotheses, the planning of experiments and the interpretation of results (Whelan and King, 2004), so-called laboratory information management systems or LIMS. In this context, the central function of LIMS is to facilitate the collection and integration of data from direct experimental observations and metadata (i.e. information that ensures the repeatability of an experiment) from various machines and instruments.

Many LIMS include statistical and even machine-learning capabilities and are used for a range of operations in pharmaceutical drug development and manufacturing, such as drug discovery, quality control in drug production and pathology for disease diagnosis. Forming the administrative backbone of laboratories, LIMS become central components of overall corporate IS, effectively functioning as business systems in most leading pharma firms. Moreover, the centrality of LIMS to the pharmaceutical industry can also be explained by increasingly strict requirements imposed by regulatory authorities such as the FDA (Food and Drug Administration) and the EMA (European Medicines Agency) for quality-control systems that ensure the generation of high-quality data for drug evaluation. To meet such regulatory requirements, there has been a gradual shift from paper-based to electronic datamanagement systems. The regulation that governs electronic submission for the FDA is 21 CFR (Code of Federal Regulations) Part 11. There is a similar regulation at the EMA in the form of Annex 11.

Although LIMS emerged in the 1980s as a rudimentary in-house method for automating manual, error-prone laboratory processes, in recent years customized systems have largely been replaced by commercial off-the-shelf LIMS (Studt, 2004). Although functions may vary somewhat between brands, the use of LIMS contributes to standardizing lab processes across locations, languages, time zones and data formats. While there are many systems suppliers, the international market is largely oligopolistic in nature with a few large, dominant vendors. Smaller suppliers cater predominantly to national markets. In India, for example, there exist a number of local LIMS brands that many Indian pharmaceutical firms use (personal communication with an international systems auditor).

\section{Method}

\section{Research approach and data collection}

The boundary-spanning nature of information-management systems (Orlikowski and Baroudi, 1991; Stahl and Brooke, 2008), as well as the outsourcing phenomenon (Handfield, 2002; Lasch and Schultmann, 2012), suggest a need to analyse the interplay between crossfunctional and inter-organizational entities. Instead of taking a monadic view, our study, therefore, adopted a multi-actor approach that sought to capture the perspectives of representatives of multiple types of organizations such as pharmaceutical clients, CROs, system-validation auditors and software vendors (local and international). We also strove to represent hierarchical levels, particularly within CROs, by including lab managers, study directors and lab workers among our interviewees. By examining multiple actors' perceptions of LIMS and their functionality, we were able to look beyond the rhetoric of efficiency and focus on how actors construct meaning as they operate LIMS on a daily basis. This, in turn, enabled us to explore the dynamics of power and resistance underlying the design and use of, as well as the rhetoric associated with, information-management systems (Lyytinen, 1992). 
Personal interviews were our main method for capturing the perspectives of the actors we identified as relevant to our study. We used our personal networks to identify three initial interviewees who served as gateways to additional study participants. Through a process of snowballing, we interviewed 23 individuals between March 2018 and October 2019 (Table 1). All interviews except for two were conducted via Skype or Zoom, which provided a convenient mode of qualitative inquiry (Hanna, 2012). Interview sessions lasted between 20 and $90 \mathrm{~min}$.

Reflecting extreme levels of confidentiality surrounding drug-discovery research, many

interviewees spoke to us on the condition of not being recorded. Therefore, only 10 interviews were digitally recorded and transcribed verbatim. In cases when interviews could not be recorded, we took plentiful notes. For purposes of anonymity, the names of all participants mentioned in the following sections have been changed.

Two interviewees were particularly helpful in generating an understanding of technical aspects of drug-discovery and information-management systems and we carried out ongoing conversations with them throughout the data-collection process. The insights they

\begin{tabular}{|c|c|c|c|c|c|}
\hline Name & Organization type & Position & Length of interview & Interview date & \\
\hline Nimish & $\mathrm{CRO}$ & Marketing & $30 \mathrm{~min}$ & 2 April 2019 & \\
\hline Dr Nitin & $\mathrm{CRO}$ & Lab scientist & $30 \mathrm{~min}$ & 2 April 2019 & \\
\hline Dr Desai & $\mathrm{CRO}$ & CEO Director & $30 \mathrm{~min}$ & 1 June 2019 & \\
\hline Dr Gosh & $\mathrm{CRO}$ & CEO director & $1 \mathrm{~h} 10 \mathrm{~min}$ & 28 March 2019 & \\
\hline Dr Seth & $\mathrm{CRO}$ & CEO director & Via email & April-June 2019 & \\
\hline Supriya & $\mathrm{CRO}$ & Lab worker & $40 \mathrm{~min}$ & 22 August 2018 & \\
\hline Sujata & $\mathrm{CRO}$ & Lab worker & $30 \mathrm{~min}$ & 04 March 2019 & \\
\hline Ritesh & $\mathrm{CRO}$ & Lab manager & 1 h 5 min (2 times) & 07 June 2018, 4 March 2019 & \\
\hline Shivani & $\mathrm{CRO}$ & Lab worker & $30 \mathrm{~min}$ & 18 March 2019 & \\
\hline Dr Shalini & CRO & Study director & $50 \mathrm{~min}$ & 10 April 2019 & \\
\hline Dr Pooja & CRO & Lab scientist & $30 \mathrm{~min}$ & 13 April 2019 & \\
\hline Ajita & $\mathrm{CRO}$ & Lab worker & $30 \mathrm{~min}$ & 23 April 2019 & \\
\hline Vyas & $\begin{array}{l}\text { Technology } \\
\text { distributor }\end{array}$ & Marketing executive & $\begin{array}{l}45 \text { min (recorded) } \\
\text { via skype ingoing } \\
\text { text messages }\end{array}$ & $\begin{array}{l}\text { Ongoing Since March } 2018 . \\
\text { Interview } 5 \text { May } 2019\end{array}$ & \\
\hline Rupali & Client firm (Pharma) & Study coordinator & $2 \mathrm{~h} 45 \mathrm{~min}$ (2 times) & $\begin{array}{l}2 \text { March 2018, } 5 \text { September } \\
2018\end{array}$ & \\
\hline Asha & Client firm (Pharma) & Study coordinator & $30 \mathrm{~min}$ & 20 August 2018 & \\
\hline Martin & Client firm (Pharma) & Project coordinator & $3 \mathrm{~h} 30 \mathrm{~min}$ (3 times) & $\begin{array}{l}22 \text { March 2018, } 15 \text { May } \\
\text { 2018, August } 2019\end{array}$ & \\
\hline Neha & $\begin{array}{l}\text { System validation } \\
\text { firm }\end{array}$ & Auditor & $55 \mathrm{~min}$ & 16 May 2019 & \\
\hline Paul & $\begin{array}{l}\text { LIMS vendor } \\
\text { (International) }\end{array}$ & $\begin{array}{l}\text { Installation } \\
\text { coordinator }\end{array}$ & $30 \mathrm{~min}$ & 28 March 2019 & \\
\hline Ashish & $\begin{array}{l}\text { LIMS vendor } \\
\text { (International) }\end{array}$ & $\begin{array}{l}\text { LIMS installation } \\
\text { consultant }\end{array}$ & $30 \mathrm{~min}$ & 30 April 2019 & \\
\hline Harsh & $\begin{array}{l}\text { LIMS vendor } \\
\text { (International) }\end{array}$ & LIMS sales executive & $50 \mathrm{~min}$ & 18 April 2019 & \\
\hline Kavita & $\begin{array}{l}\text { LIMS vendor } \\
\text { (International) }\end{array}$ & LIMS sales executive & $\begin{array}{l}30 \text { min (via skype } \\
\text { text) and emails }\end{array}$ & April 2019-May 2019 & \\
\hline Kiran & $\begin{array}{l}\text { LIMS vendor } \\
\text { (International) }\end{array}$ & Software developer & $2 \mathrm{~h} 20 \mathrm{~min}$ (2 times) & March 2018, May 2019 & \\
\hline Prateek & LIMS vendor (Local) & Marketing & $45 \mathrm{~min}$ & 16 October 2019 & Table 1. \\
\hline Mehul & LIMS vendor (Local) & Software developer & $30 \mathrm{~min}$ & 18 October 2019 & Interviewees \\
\hline
\end{tabular}


CPOIB 18,3

\section{8}

offered during initial interviews formed the basis of a semi-structured interview guide to be used with other study participants, comprising the following broad themes:

- Issues related to the service-provider selection. Information typically required of a provider (CRO) to be considered for international contracts, such as a service provider's capabilities, equipment, experience in specific areas, reputation, certifications, financial data and data on sustainability work.

- Information related to the selection of LIMS. Which brand of LIMS is used, considerations when choosing a LIMS provider and commonalities and differences between international and local brands.

- LIMS and work processes. Functions of LIMS, the role of LIMS in work processes, how LIMS shape work processes and challenges related to using these systems.

To elicit participant interpretations, interviews mostly took the form of informal conversations and interviewees were encouraged to share their thoughts and experiences freely through frequent follow-up questions. All interviews were conducted by one author. The decision to cease data collection was based on saturation, i.e. when additional interviews yielded few new insights. Along with the interviews, we examined LIMS user manuals and implementation guidelines. These sources were complemented by publicly available material from LIMS providers such as sales brochures, webpages and sectorial documents.

\section{Data analysis}

To capture the interplay between cross-functional and inter-organizational entities and to critically examine this interplay in terms of neo-colonial politics, we performed an interpretive analysis involving a dialogical movement between text, context and theory (Mantere and Ketokivi, 2013). Although one author conducted the fieldwork, both authors participated in the analysis, thereby challenging the preunderstanding arising from the interview situation.

The analysis was carried out in two main stages. Guided by postcolonial sensitivity to power and resistance, in the first stage we searched interview transcripts and notes for passages indicating how interviewees construct and favour versions of reality. We focused in particular on accounts showing how interviewees position certain groups and interests and how, in the process, they relate to elite interpretations of how business processes "should" be performed, measures taken to control these processes and how deviations from mandated practices were described. In the identification of such accounts, we encountered many descriptions of LIMS as "necessary" to increase traceability and process efficiency and of how the procurement of LIMS enabled some local CROs to become more competitive in the international market. We also found accounts criticising LIMS as invasive, influencing work processes negatively and reducing work satisfaction among local CRO employees.

In the second stage of the analysis, we sorted these accounts into broader themes. This analysis involved the use of theory and prior empirical work to continuously challenge our categorizations of accounts and contributed to sharpening the study's framework to focus more specifically on the role of IS in outsourcing. After multiple iterations, this stage of analysis resulted in the shaping of three particularly prominent themes relating to LIMS and neo-colonial control:

(1) how LIMS contribute to controlling local markets,

(2) how LIMS act as inter-organizational control tools and

(3) how LIMS function to shape the nature of local R\&D work practices. 
In the subsequent section, we present and discuss our findings in relation to these themes.

Outsourcing of

\section{Empirical findings and analysis}

In this paper, we argue that discourse and practices surrounding information software such as LIMS can be critically examined through the lens of neo-colonial control. Our analysis suggests that a LIMS acts as a neo-colonial control tool at the industry level, the organizational level and at the level of work practices. Here, we first explore the role of LIMS in offshore vendor selection and investigate how preferences for international LIMS brands can shape both local CRO and local LIMS markets while simultaneously enabling Western pharmaceutical firms to extract maximum value. We subsequently discuss how LIMS shape work processes at local CROs to minimize any risks to client firms. In the following section, we examine how LIMS reshape the nature of R\&D work to limit local learning that may ultimately challenge Western pharmaceutical firms.

\section{The role of laboratory information management systems in controlling the local contract research organization industry}

Informatics infrastructure is a crucial factor in the evaluation and selection of third-party service providers (Ageron et al., 2013) and is becoming more important as core processes are externalized and as supply chains are internationalized. Our analysis shows how requirements placed on the usage of informatics systems and CROs' responses to such requirements shape both the CRO industry and the local LIMS industry. In particular, the distinction between LIMS users and non-users was a recurring theme in our interviews and participants consistently pointed out that a central criterion for being awarded international contracts is that a CRO possesses an internationally competitive laboratory informationmanagement infrastructure. Dr Gosh, the CEO of a CRO with several international clients, explained:

The manufacturers and companies from other countries, they prefer CROs which have validated lab information systems interfaced with data acquisition systems. So that gives an advantage. Many of the CROs do not have at this point of time [...] validated information systems. They are working with manual $[\ldots]$ systems, which $[\ldots]$ becomes a question of acceptance or not to place the study [i.e. whether to contract the CRO].

Several interviewees related client firms' emphasis on LIMS to the regulatory requirements surrounding drug development. As the US is the largest single market for pharmaceuticals, international drug development is shaped largely to meet FDA requirements. An important challenge for pharmaceutical clients is therefore ensuring that geographically dispersed outsourced work complies with FDA regulations. The FDA accepts data and documents from studies conducted abroad only if a study was conducted in accordance with good lab practice (GLP) and if the FDA is able to validate the data from the study through an onsite inspection and audit trail (electronically). Furthermore, the FDA requires pharmaceutical firms to comply with its regulation regarding electronic submission i.e. CFR 21 Part 11. Broadly, this means that all data must be traceable through the software flow from data capture to final submission of documents for drug approval and that all activities performed in labs must be recorded and traceable to specific individuals (i.e. lab workers). At any time, regulatory bodies can audit documents and files in the system to assess accuracy and completeness against raw data (www.FDA.gov). Pharmaceutical clients' insistence on local CROs' use of LIMS thus largely rests on the argument that it enables and ensures regulatory 
CPOIB 18,3

compliance, particularly with the FDA. LIMS, therefore, acts not only as an information management tool or business system but also as a regulatory technology. Many interviewees in different positions in the drug manufacturing industry emphasized such benefits of LIMS. For example, Vyas, a representative of a LIMS distributor, argued: "[with LIMS] you completely comply [and] everything will be transparent. But when you do the manual things, there are chances of breeches, of adjustments to the sample".

Having LIMS at vendor sites thus has direct benefits for client firms as these systems enable CROs to gather, analyse and store data on behalf of clients while simultaneously limiting the fear of data malfeasance. At the same time, implementing a validated information management system represents a considerable initial financial investment, requires ongoing licence fee payments and adaptation of the internal organization of a CRO. Therefore, many smaller CROs lack the resources they need to make such a commitment (Riggins and Mukhopadhyay, 1994). In this vein, lab manager Ritesh noted:

The implementation of LIMS is more costlier so the [small] companies [...] cannot afford this solution, only the big companies dealing in 100-200 crores [USD 15-30 million] can bear these costs.

While LIMS thus represents a ready-made tool through which geographically dispersed CROs are incorporated into the transnational pharmaceutical production network, it effectively shapes the local CRO industry by creating distinct segments of CROs - those that have LIMS and who may therefore compete for international contracts and those that cannot. The former represents an elite segment of vendors, a comprador class of firms (Boussebaa et al., 2014) tailored to the needs of Western firms by enabling the latter to benefit from wage disparities while simultaneously maintaining levels of regulatory compliance similar to what can be achieved in an internal, hierarchical setting. The design of information-management software, as well as requirements regarding its use thereby influence industry structures by creating uneven competition between local vendors and by promoting the concentration of capital flows to a few local firms.

As several study participants argued, however, it may not be sufficient to have in place a validated informatics infrastructure to be considered for international contracts. Western clients also prefer - and in many cases demand - that a CRO has the same brand of LIMS as a client. Kavita, the representative of a leading LIMS producer, explained the significance of this requirement:

Everything is easier - the client can create their studies as they do in-house, and then send the completed study design to the CRO to be imported into their system. This enables seamless exchange and data transfer, you know. It will also ensure commonality in the accepted level of process validity required for a GLP [good lab practice] study.

CRO study director Dr Shalini also argued that clients prefer particular brands of LIMS as these are known to regulatory authorities. He commented:

$[\ldots]$ it becomes complicated when I have to work with the regulatory [...] agencies [that] know that the ' $x$-and-y' system is used and they are aware of that technology. So, that is why there will always be a preference for international brand of LIMS as opposed to Indian.

Familiarity with LIMS is not the only reason clients prefer well-known international brands, however. According to some participants, international clients often distrust local (Indian) brands of LIMS as they fear data malfeasance and loss of control. This reluctance relates primarily to perceptions that local LIMS vendors may have access to critical components of the system and can extract data or effect attacks such as malicious code injections. Dr Gosh explained the clients' discomfort with local LIMS: 
Even in Indian LIMS you find [FDA compliance], [but] if you go for a local LIMS [your] integrity will be questioned. The coding and other things will be developed here in India itself. So, see, we are from Asian region [and] therefore every moment people start suspecting - even if you do certain things correct also still there is always a chance for suspicion. They [international clients] think there is a chance of decode [interviewee laughs].

Outsourcing of $\mathrm{R} \& \mathrm{D}$ to emerging markets

291

Dr Gosh thus argued that foreign clients distrust locally produced LIMS, fearing that the integrity of sensitive data may be compromised. Other study participants also argued that foreign regulatory bodies (such as the FDA and EMA) may be less comfortable with local systems than those of leading Western manufacturers, which may negatively affect drug approval processes. Dr Shalini, study director at a CRO concluded:

[... . ] if the CRO is using [a leading brand of LIMS], then lesser questions are asked by FDA and auditors. [...] But having said that, there might be local LIMS that have the compliance features and all that but [...] the clients think [there will be] issues with data protection.

Requiring particular brands of LIMS may thus further emphasize the differences between the segments of CROs that undertake service for Western clients and those serving local drug-manufacturing firms. Although there may be little difference in the design, functionality and features of LIMS from leading international suppliers and domestic suppliers, there is a significant cost difference and while many CROs may be willing to bear the cost of local LIMS, it may be impossible to bear the investment of the LIMS brand that a client prefers. In the words of Vyas:

[...] all those things [LIMS] are also expensive and they find it very difficult to cope with the competition [...]. So they are trying to balance [...] complete automated systems and profit margins.

Requirements for informatics infrastructures and the use of particular brands of informatics systems not only shape competition in the CRO market but also has effects on the LIMS production market. By pressurizing local firms to use brands of information-management systems with whose producers clients have longstanding collaborative relationships, Western clients prevent competition with Western information-management system producers and undercut the development of the local LIMS industry. A neo-colonial reading of pharmaceutical clients' discomfort with locally produced LIMS also points to insecurities in relation to India's reputation for IT knowledge and skills (Mckenna, 2011; Amrute, 2016). As Dr Shalini summarized, "all said and done, the IT skills are much, much higher here in India - we have kind of experienced people here who can do much better". Western clients' insecurities may thus also relate to the competencies of the Indian IT industry and how local manufacturers can outsmart clients with their coding skills or by stealing their data. These insecurities are not only reflected in fears related to data violation but are also packaged in a rhetoric wherein foreign regulatory authorities are understood as unable to handle data produced by and stored in locally produced systems. Thereby, the integrity and the value of Indian LIMS are fundamentally questioned, maintaining the status quo on the international LIMS market.

\section{LIMS as a tool of inter-organizational control and the resistance it generates}

While the primary function of any information-management system is to automate work and streamline data collection (e.g. in accordance with regulatory requirements), given its ability to informate (Zuboff, 1988) - e.g. generate real-time information and store data over a period of time - such technology also enables close monitoring of outsourced work (Aron et al., 2008). In this section, we first engage with how LIMS acts as a control tool by 
CPOIB 18,3

affording real-time, remote and retrospective monitoring that largely benefits Western client firms. To avoid technological determinism when analyzing the controlling power of software such as LIMS, we also consider to how local CRO staff resist the system's monitoring gaze (Bain and Taylor, 2000; Richardson and Howcroft, 2006).

Pharmaceutical clients increasingly rely on LIMS to monitor CROs' work processes and to improve their performance. In line with what studies on the automation of call-centre work find, clients use LIMS to increase rather than reduce their presence in and exercise direct control over, outsourced lab work (Poster, 2011). LIMS, in this sense, enable clients to participate actively in the daily operations of CROs while simultaneously being physically absent. LIMS thereby acts as a remote virtual manager performing real-time monitoring. Dr Ghosh explained this feature of LIMS:

The moment my experimental data is available in the system, at the other end they [clients] can open and see whether the experiment has passed or failed or what they [the results] have come to be.

Real-time access to evaluate progress and results is not the only feature that LIMS affords client firms but also allows a client to assess the performance of CRO staff. For example, its inbuilt feature related to user privilege and rights enables detection of data manipulation or the performance of other unauthorized tasks at an individual level. CRO lab manager Ritesh explained:

Everybody has the pressure, like 'what was your failure rate'. So if your studies is going [to fail] or data is going to be fail, [people] will make individual correction in the data. [... . you can [only] control all these things by putting in proper software solutions.

In this regard, LIMS becomes a means of disciplining lab workers as the software is a constant but invisible monitoring presence (Lyon, 1993), gathering evidence of workers' performance and supporting performance analysis and feedback. Clients can also use performance reports generated by LIMS to hold CROs accountable if contractually agreedupon procedures are not followed. As Dr Shalini cautioned, "[if] at any given point of time there is a suspect or breach he [the client] can take you to court, he can discontinue the contract so there is a very clear procedure that is in place". LIMS thereby subjects workers to extreme levels of measurement, monitoring and "panoptic" control (Fernie and Metcalf, 1998), in many ways similar to call-centre work.

While LIMS affords real-time monitoring, it nonetheless makes day-to-day monitoring unnecessary due in part to its capacity to store data on all lab processes, allowing clients to monitor events or processes retrospectively. As Ritesh, the CRO lab manager, observed:

They [clients] are not coming directly to the CRO labs and they are just visiting them and then inspecting them sometimes, they do at the later stage, so that is the retrospective inspection. [...] the LIMS are doing the continuous monitoring for them [the client].

Both client firms and regulatory authorities can undertake retrospective inspections. It is also a regulatory requirement (e.g. according to the FDA's CFR21 part 11) that data must be stored by the information-management system for extended periods, reaching far beyond the introduction of the drug to the market. These regulatory demands are in place in case of adverse FDA findings or drug recalls. As a CRO manager, Dr Desai explained:

You can reconstruct studies even after nine or ten years also; what happened on one particular day who conducted [the study], when and which instrument was used and what was the validated 
state of that instrument, which buffer was used, how it was prepared, and which instrument was used for that, if that instrument was under maintenance [. . . ] whether it was qualified.

Although holding no intellectual property rights over the tested molecules or any test results, CROs are required to store data long after the terms of a contract are met and are required to share data with clients and regulatory authorities on demand. They are also held accountable for the integrity of data during this period, although data ownership and all the profits that accrue from data remain with clients. For example, Dr Desai observed that:

[... . a CRO will never share the patent rights [...]. The patent is completely their [the client's] right. Even not only the patent, even the standard testing protocol, is the property of the sponsor.

Along similar lines, a CRO manager, Dr Seth, noted:

[... . there is no form of 'sharing' of results or data between clients and CRO. For any study that is conducted, the particular client remains the owner of the data and results.

In several ways, the informating abilities (Zuboff, 1988) of LIMS thus work to promote and sustain the interests of pharmaceutical clients through its remote and real-time monitoring abilities, directing CROs' internal work processes to the last detail. In addition to spatially expanding the gaze of Western clients and regulatory bodies, LIMS also serves to extend their gaze temporally by ensuring that vendors can retrospectively be held accountable for data quality and integrity over long periods of time. Simultaneously, data and knowledge generated by a CRO remain entirely the property of its client through intellectual property regulations and policy arrangements (Mir and Mir, 2009). LIMS software thereby affords clients managerial control over outsourced processes similar to what could previously be achieved only within an organization, generating a mode of organizing that eliminates much of the risk associated with outsourcing.

In spite of the seemingly all-encompassing nature of control elements inbuilt into informating technologies such as LIMS, it cannot be assumed that such control measures go unchallenged and that CRO lab workers become accomplices, eagerly selfdisciplining at the command of international clients. Our empirical work reveals on the contrary many ways in which CRO lab workers and managers resist LIMS' relentless gaze. A common resistance strategy among lab workers who carry out daily lab work is to withhold reporting of changes made in data in spite of the fact that any changes are continuously recorded by the system. Changes in databases are often performed to correct for negligence or human error - a common occurrence in any lab work, according to several of our interviewees. Neha, an auditor for a system validation firm, gave an example of a common human error while performing experiments, an error that lab workers prefer not to account for:

They [lab workers] forget the timings, [. . .] they have to do something in a hour and they go for lunch and they forget, they come after two hours, right? They have to kind of error recalibrate or account for the mistake they have done, [. . . ] so they [manipulate data].

When such errors occur, lab workers may thus not admit to or report the changes made, to an immediate lab manager. While there can be several reasons for not reporting an error, Dr Gosh argued that local CROs may not always understand the relevance of reporting errors:

Sometimes, you know, they misunderstand this concept and they assume that there is no need to inform [anyone of] small things - mistakes happening - but then it has severe impact on the pipeline product. So therefore when such things happen, CROs should understand the requirement and the expectation of the clients.
Outsourcing of R\&D to emerging markets

\section{$-$}


CPOIB 18,3

The fear of job loss may also lead lab workers not to report changes to their supervisors, in spite of insistent instructions. Neha illustrated:

Now we have trainers and leaders [clients] who keep coming and saying, people on the conference who speak, sach bolo [speak the truth], honesty dikhao [show honesty], boss ko jake bol do [go and tell the boss]. But you know you will lose your job, OK?

Although the rationale for implementing LIMS is to direct outsourced lab work and to assess CRO performance, these ambitions may also be subverted by the hierarchical structures of lab work; a lab worker is accountable to an immediate local lab manager/study director rather than directly to a client. While failure to report errors or attempts to adjust for errors may reflect negatively on lab managers in their role as lab supervisors, the risk of detection for lab workers is often not immediate. As Neha further explained: "In many places, they [lab workers] aren't scared of the clients. The clients can always be fooled and [manipulated]. So when such a thing happens [an error] they say 'let's make up some stories, do something, but not report".

Not all instances of data manipulation are the result of human error, though. Cases of manipulation to improve the results of experiments were cited by several participants, although they were typically attributed to CROs who had gone out of business or were currently involved in non-compliance cases pursued by the FDA. One such practice relates to performing parallel experiments, where CROs run the same experiments twice to manipulate or interchange results. Lab manager Ritesh explained:

Some of the companies, they are just keeping like a parallel lab [. . . So if they want to manipulate things, they can do that job and that data. Then they are getting compliance issues. They are not showing [original data] to anyone [...].

Attempts to manipulate test data on the scale described by Ritesh represent attempts by lab managers and upper management to handle the consequences of minor errors and, thereby, to subvert the controlling nature of LIMS. We thus see examples of employees at various levels attempting to interrupt the dominant narrative in which lab technologies are presented as efficient tools for safeguarding data integrity. From the client perspective, the capacity of LIMS to detect unintentional errors and intentional data manipulation should foster self-disciplining behaviour among lab workers. The failure to do so relates in part to the way in which lab workers are treated as almost entirely substitutable and machine-like in the ways they perform their tasks. The advantage to the worker is the relative ease with which alternative employment can be found. Indeed, many employees may long have left their places of employment by the time their attempts to conceal errors are detected. Consequences for managers may be more severe as, even when unintentional errors occur, they are held accountable by clients and regulatory authorities for failing to report errors. This generates more drastic precautionary measures, such as duplicating experiments. These examples thus show how employees at various hierarchical levels attempt to interrupt the dominant narrative in which their work is guided by an allseeing technology that acts to align their interests with those of regulators and clients. The failure to achieve this alignment highlights the limits of technical control in outsourcing work, challenges whether clients can achieve relationships with vendors allowing for levels of control possible in an intra-organizational setting, and reveals the intersection of multiple forms of authorities and agencies that inhabit the technical panorama (Poster, 2011). 
The impact of laboratory information management systems on $R \& D$ work and lab workers Information technologies not only record scientific activities but they also guide how these activities are performed (Aneesh, 2006). In this section, we discuss how increasing reliance on LIMS is changing the nature of lab work by routinizing processes, thereby restricting scientific autonomy and reshaping how local scientists work to meet the needs, and mitigate the fears of, global pharmaceutical organizations. We also discuss how such standardization makes lab work increasingly target-oriented and volume-driven, leading to deskilling and job dissatisfaction among lab workers.

Several study participants commented that LIMS software has a strong standardizing and normative influence on lab work, making it possible to break complex tasks down into standardized sections to be carried out according to predetermined routines. This often means that lab workers literally follow experimentation steps as scripted in the software. Installation consultant Ashis commented on this significant feature of LIMS: "it's predetermined in that way - each and every step. So you have predefined steps of doing lab work". Vyas, another representative of the same LIMS manufacturer, argued that "[t]he system [...] standardises lab work to globally accepted norms and ensures no deviations".

Routinization of R\&D activities through automated work-management and control systems such as LIMS enables client firms to break drug discovery into small modules with specific targets that can be outsourced to a range of different CROs (Vora, 2013). This ability of LIMS to pry apart complicated processes thereby facilitates the outsourcing of work previously thought too complex to outsource or too risky to offshore to single vendors. As CROs work on only a miniscule part of the development of a particular drug, they are often even unaware of their role in a larger project (Kamat, 2014). As Dr Shalini explained: " $A$ CRO is just doing one miniscule task; often they don't know what drugs they are working on". Such fragmentation of lab work processes protects against misappropriation of information developed in the outsourced R\&D process (Contractor et al., 2011). It also curtails horizontal knowledge development in a CRO, preventing local vendors from developing process and product knowledge that may, ultimately, threaten client organizations.

As CROs perform only small pieces of a large puzzle, the possibility of discovery beyond meeting a specified target is also eliminated. Scientists' work is thus largely demarcated by the control tool, removing elements of creativity and independence that are otherwise characteristic of knowledge-intensive work (Alvesson, 1995; Kärreman et al., 2002). In the traditional model of biomedical research, failure, human error and serendipity were also natural components that were not only tolerated but even encouraged as they generated learning and moved medical research down new trajectories (Siddiqui et al., 2010). Work performed under automated control systems such as LIMS defies such conventional definitions of innovation as the control tool erodes scientific autonomy. In our interviews, lab workers at various hierarchical levels pointed out how being connected to LIMS has changed their work, in particular how they are expected to perform in a more programmatic way (Aneesh, 2006). Study coordinator Rupali pointed out:

I think it [LIMS] constricts our work as scientist. Yes, I see there are advantages, but it restricts flexibility. When I did experiments without it, it was different. LIMS and also other automation systems make it very mechanical.

Along the same lines, Project coordinator Martin commented that with LIMS there is "no place for creativity, curiosity, that kind of stuff, you know. [...] Good discovery was done before these [LIMS] came to market and people did good lab work".

LIMS thus supports a mode of outsourcing that enables a client firm to benefit from local market conditions but prevents any substantial local learning. The emphasis of LIMS on
Outsourcing of R\&D to emerging markets

295 
CPOIB 18,3

supporting the fulfilment of managerial control objectives also creates lab workflows that are highly target-driven and repetitive. R\&D work is thereby rendered largely devoid of worker discretion, with little importance attached to professional (scientific) expertise (Braverman, 1974; Trusson et al., 2018) and little space in which to pursue the professional objectives of individual scientists. This suggests that, when transferred to developing countries through outsourcing, the supposed high-end nature of scientific work looks remarkably more like outsourced low-skill, repetitive work than knowledge-intensive work (Vora, 2013).

In many ways, the stories some participants related reflect findings of research on call centres where researchers have long argued that IT-induced control leads to increasing work dissatisfaction and disempowerment (Batt et al., 2009). As lab workers are subjected to task routinization, lack discretionary power, engage in the repetitive use of mundane skills and are subject to constant performance surveillance, de-skilled scientific work loses the characteristics that attracted employees to science in the first place. CRO lab worker Supriya reflected that outsourced research work

[...] should be more research-oriented and not so much target-oriented like production. Target is, like, 'you have to complete this, this and this'. So that is there, in your mind, that I have to complete this target - but it has to be research and not only target.

Similar to findings of research on call centres, some of our study participants also commented that perpetual work monitoring becomes an effective means of pressurizing them to intensify their work (Taylor and Bain, 1999; Callaghan and Thompson, 2001), leading to high levels of stress (Batt et al., 2009). Auditor Neha reflected on this situation in CROs:

You should see the way people work in India. They start morning 8 clock until 11 at night, you know. It's somebody working for 12 hours, 13 hours. And you are working like dogs and cats then like gadha [donkey]. And for everybody like, it is very competitive, you know?

To conclude our empirical work, we thus find that the functions of LIMS that ensure compliance with regulatory bodies simultaneously generate a routinization and slicing-anddicing of R\&D work that gives little space to the development of local competencies and transforms local lab workers into de-skilled functionaries who perform highly regulated sets of tasks with decreasing work satisfaction.

\section{Concluding discussion}

A cornerstone of the neo-colonial argument is that contemporary globalization represents the enduring heritage of colonial (re)organization of production and consumption (Banerjee, 2008; Boussebaa and Morgan, 2014). The economic value of raw materials and the value extracted from labouring subjects continue to flow from producing sites in the Global South to high-consumption sites in the Global North, with such neo-colonial forms of exploitation providing a foundation for continued unequal accumulation of wealth (Vora, 2013). In this paper, we critically examine various ways in which IS support this extraction of value in the area of R\&D outsourcing to emerging markets. By examining pharmaceutical R\&D offshoring to India, we show how LIMS serve as tools of neo-colonial control by directing the broader pharmaceutical drug-development network and, at the organizational level, by mediating relationships between clients and vendors. We also show how, at the level of work practices, LIMS curtail the professional autonomy of lab workers by changing the very nature of $R \& D$ into routinized, repetitive and task-oriented work. 
The capacity of IS to monitor the execution of processes in real-time, remotely and retrospectively, emerged as a significant enabler of offshore outsourcing of R\&D work to distant markets. IS allow client firms to exert managerial control - not just in the form of monitoring but through actual intervention - in relation to outsourced high-end work while simultaneously benefiting from the low wages of high-end workers in local markets. IS thereby enable outsourcing firms to combine features of the market and the firm (Aron et al., 2008). Thus, as informatics infrastructures are established, the panoptic grid of client firms grows. Information tools simultaneously serve as regulatory technologies that bring offshore third-party service providers under the official gaze of (Western) regulatory bodies and become a key means of transmitting their mandates, presenting these as global best practices and ensuring their implementation at service providers' locations. In this way, IS strategically enable and extend a network of relations that affords client firms the ability to extract value from new locations.

Advancements in IS also facilitate the deconstruction of complex processes, thereby enabling the externalization of work that has traditionally been considered too complicated for offshore outsourcing. As service providers are contracted only to perform highly circumscribed tasks, though, they may be unaware of the role they play in the broader development process, rendering outsourced R\&D work repetitive, with limited possibilities for creativity and learning. While mainstream studies portray R\&D outsourcing as levelling the playing field and placing emerging markets on an equal footing with Western economies (Sartor and Beamish, 2014), such work still needs to convincingly show how sliced-and-diced outsourced R\&D work increases the knowledge bases of host markets. Work in this vein also needs to show how engaging in micromodularized research activities moves third-party service providers upstream in the knowledgeproducing value chain. Further, by breaking R\&D work into small components, client firms ensure that the results are of limited value to service providers and prevent knowledge leakages that could threaten intellectual property rights. The capacity of technology to break down the scientific process into commoditized work packages also suggests that scientists working for local organizations are entirely replaceable, performing near-robotized standard tasks. When transferred to developing countries through outsourcing, the supposed high-end nature of scientific work thereby shows remarkable similarity to outsourced low-end work. This is reflected also in the target-oriented nature of performance assessment, with effects on employee stress and de-skilling that align with findings of call-centre studies (Batt et al., 2009).

Demand for information-management systems also generates structural forms of domination by allowing entry into transnational production networks only to those organizations with the means to invest in such client-specified information infrastructures. In addition to directing the development of local markets for service providers, highly specific requirements imposed on information-management systems also impact the information-system market, preventing local systems producers from competing with international systems providers (Kwet, 2019).

Despite the controlling power inherent in information-management systems such as LIMS, our study has also identified and described elements of resistance that highlight particular regions of discourse and practice. Such observations counter the image of technology as an "iron cage" in which labour is trapped (Ritzer, 2000; Weber, 2001). Rather, acts of resistance by workers, such as not reporting or covering up errors, as well as resistance by managers in the form of running parallel labs, suggest that they retain power and knowledge to act within and use the "excess" left undisciplined by, such technologies (Bain and Taylor, 2000). These acts do not necessarily or even primarily, take the form of disruptive resistance, though. As shown by our findings, they become a practical tactic deployed to avert the gaze of clients without drawing attention to themselves. 
CPOIB 18,3
While we have strived to present more generalized insights into IS as a tool of neocolonial control, we recognize that our study is subject to limitations arising from our narrow focus on a specific context. In particular, the centrality given to the client-CRO relationship has obscured the class, caste and gender positions of those used within the value chain of offshored work in India (Radhakrishnan, 2007; Upadhya, 2007). A large number of marginalized groups are used by the CRO industry in the capacity of lab workers, nurses and - not least - volunteers in clinical trials (SunderRajan, 2006). Their work is often devalued and made invisible in relation to the work of employees inhabiting upper echelons, such as study directors, lead scientists and top management. This discrimination is rigidly aligned with long-established patterns of privilege and inclusion associated with the Indian caste system. Future research should therefore attend to the enabling role of IS in reproducing historical patterns of dominance in the host-country context, not only in pharmaceutical offshoring but also in other knowledge-intensive industries that certainly rely on substantial, but often unrecognized, contributions of the marginalized.

To conclude, our study has broader societal implications. Our work, in particular, highlights the dangers inherent in considering IS as value-free tools that only serve to increase the efficiency of organizational operations, inter-organizational exchange and global trade. Policymakers and other governing bodies need to critically review how IS and work automation contribute to reproducing global relations based on colonial structures, how they support local hierarchies of organizations and how they enable worker exploitation. Rising levels of automation and the implementation of increasingly efficient digital monitoring systems across industries will otherwise leave less and less space to challenge existing global and local inequalities.

\section{References}

Adobor, H. (2012), "Ethical issues in outsourcing: the case of contract medical research and the global pharmaceutical industry", Journal of Business Ethics, Vol. 105 No. 2, pp. 239-255.

Ageron, B., Gunasekaran, A. and Spalanzani, A. (2013), "Is/IT as supplier selection criterion for upstream value chain”, Industrial Management and Data Systems, Vol. 113 No. 3, pp. 443-460.

Alcaraz, J., Domènech, M. and Tirado, F. (2012), "eHR software, multinational corporations and emerging China: exploring the role of information through a postcolonial lens", Information and Organization, Vol. 22 No. 2, pp. 106-124.

Alvesson, M. (1995), The Management of Knowledge-Intensive Companies, De Gruyter, New York, NY.

Amrute, S. (2016), Encoding Race, Encoding Class: Indian IT Workers in Berlin, Duke University Press, Durham.

Aneesh, A. (2006), Virtual Migration: The Programming of Globalization, Duke University Press, Durham.

Aneesh, A. (2009), "Global labor: algocratic modes of organization”, Sociological Theory, Vol. 27 No. 4, pp. 347-370.

Aron, R., Bandyopadhyay, S., Jayanty, S. and Pathak, P. (2008), "Monitoring process quality in off-shore outsourcing: a model and findings from multi-country survey", Journal of Operations Management, Vol. 26 No. 2, pp. 303-321.

Bain, P. and Taylor, P. (2000), “Entrapped by the 'electronic panopticon’? Worker resistance in the call Centre", New Technology, Work and Employment, Vol. 15 No. 1, pp. 2-18.

Bain, P., Watson, A., Mulvey, G., Taylor, P. and Gall, G. (2002), "Taylorism, targets and the pursuit of quantity and quality by call Centre management", New Technology, Work and Employment, Vol. 17 No. 3, pp. 170-185.

Banerjee, B. (2008), “Necrocapitalism”, Organization Studies, Vol. 29 No. 12, pp. 1541-1563. 
Basi, J.T. (2009), Women, Identity and India's Call Center Industry: Close Calls and Hang Ups, Outsourcing of Routledge, London.

Batt, R., Doellgast, V. and Kwon, H. (2006), "A comparison of service management and employment systems in US and indian call centres", in Collins, S. and Brainard, L. (Eds), Offshoring White Collar Work, Brookings Institution Press, Washington, DC, pp. 335-372.

R\&D to

emerging markets

Batt, R., Holman, D. and Holtgrewe, U. (2009), “The globalization of service work”, Ir Review, Vol. 62 No. 4, pp. 453-488.

Boussebaa, M. and Morgan, G. (2014), "Pushing the frontiers of critical international business studies: the multinational as a neo-imperial space", Critical Perspectives on International Business, Vol. 10 Nos 1/2, pp. 96-106.

Boussebaa, M., Sinha, S. and Yiannis, G. (2014), "Englishization in offshore call centers: a postcolonial perspective", Journal of International Business Studies, Vol. 45 No. 9, pp. 1152-1169.

Braverman, H. (1974), Labor and Monopoly Capital. The Degradation of Work in the Twentieth Century, Monthly Review Press, New York, NY.

Budhwar, P., Luthar, H.K. and Bhatnagar, J. (2006), "The dynamics of HRM systems in indian BPO firms", Journal of Labor Research, Vol. 27 No. 3, pp. 339-360.

Callaghan, G. and Thompson, P. (2001), "Edward revisited: technical control and call centres", Economic and Industrial Democracy, Vol. 22 No. 1, pp. 13-37.

Cohen, L. and El-Sawad, A. (2007), "Lived experiences of offshoring: an examination of UK and Indian financial service employees' accounts of themselves and one another”, Human Relations, Vol. 60 No. 8, pp. 1235-1262.

Contractor, F.J., Kumar, V., Kundu, S. and Pedersen, T. (2011), "Global outsourcing and offshoring - in search of the optimal configuration for a company", in Contractor, F.J., Kumar, V., Kundu, S. and Pedersen, T. (Eds), Global Outsourcing and Offshoring, Cambridge University Press, Cambridge, pp. 3-47.

Differding, E. (2014), "Drug discovery alliances in India - indications, targets and new chemical entities", ChemMedChem, Vol. 9 No. 1, pp. 43-60.

Fernie, S. and Metcalf, D. (1998), (Not) Hanging on the Telephone: Payment Systems in the New Sweatshops, London School of Economics, London.

Fernandez-Stark, K., Bamber, P. and Gereff, G. (2011), "The offshore services value chain: upgrading trajectories in developing countries", International Journal of Technological Learning, Innovation and Development, Vol. 4, pp. 206-234.

Garson, B. (1988), The Electronic Sweatshop: how Computers Are Transforming the Office of the Future into the Factory of the past, Simon and Schuster, New York, NY.

Glickman, S.W., McHutchison, J.G., Peterson, E.D. and Cairns, C.B. (2009), "Ethical and scientific implications of the globalization of clinical research", New England Journal of Medicine, Vol. 360 No. 8, pp. 816-823.

Irani, L.C. and Dourish, P. (2009), “'Postcolonial interculturality”, Proceedings of the 2009 International Workshop of Intercultural Collaboration, pp. 249-252.

Kamat, V.R. (2014), "Fast, cheap and out of control? Speculations and ethical concerns in the conduct of outsourced clinical trials in India", Social Science and Medicine, Vol. 104, pp. 48-55.

Kärreman, D., Sveningsson, S. and Alvesson, M. (2002), "The return of the machine bureaucracy? Management control in the work settings of professionals", International Studies of Management and Organization, Vol. 32 No. 2, pp. 70-92.

Kwet, M. (2019), "Digital colonialism: US empire and the new imperialism in the global South", Race and Class, Vol. 60 No. 4, pp. 3-26.

Lankshear, G., Cook, P., Mason, D., Coates, S. and Button, G. (2001), "Call Centre employee's responses to electronic monitoring: some research findings", Work, Employment and Society, Vol. 15 No. 3, pp. 595-605. 
CPOIB 18,3

Lasch, R. and Schultmann, F. (2012), "Editorial for special issue: interfaces in supply chains", International Journal of Physical Distribution and Logistics Management, Vol. 42 No. 6, pp. 520-525.

Lyytinen, K. (1992), "Information systems and critical theory”, in Willmott, H. and Alvesson, M. (Eds), Critical Management Series, Sage publication, London, pp. 159-180.

McKenna, S. (2011), "A critical analysis of North American business leaders' neocolonial discourse: global fears and local consequences", Organization, Vol. 18 No. 3, pp. 387-406.

Mantere, S. and Ketokivi, M. (2013), "Reasoning in organizational science", Academy of Management Review, Vol. 38 No. 1, pp. 70-89.

Mayasandra, R., Pan, S.L. and Myers, M.D. (2006), "Viewing information technology outsourcing organisations through a postcolonial lens", in Trauth, E., Howcroft, D., Butler, T., Fitzgerald, B. and DeGross, J. (Eds), Social Inclusion, Societal and Organisational Implications for Information Systems, Springer, Berlin, pp. 381-396.

Menzies, H. (1996), Whose Brave New World? The Information Superhighway and the New Economy, Between the Lines, Toronto.

Mir, R. and Mir, A. (2009), "From the colony to the corporation: studying knowledge transfer across international boundaries", Group and Organization Management, Vol. 34 No. 1, pp. 90-113.

Mir, R., Banerjee, S.B. and Mir, A. (2008), "Hegemony and its discontents: a critical analysis of organizational knowledge transfer", Critical Perspectives on International Business, Vol. 4 Nos 2/3, pp. 203-222.

Mirchandani, K. (2004), "Practices of global capital: gaps, cracks and ironies in transnational call centres in India", Global Networks, Vol. 4 No. 4, pp. 355-373.

Mirchandani, K. (2012), "Learning racial hierarchies: communication skills training in transnational customer service work", Journal of Workplace Learning, Vol. 24 No. 5, pp. 338-350.

Mirowski, P. and Van Horn, R. (2005), "The contract research organization and the commercialization of scientific research", Social Studies of Science, Vol. 35 No. 4, pp. 503-548.

Mitev, N. (2006), "Postmodernism and criticality in information systems research: what critical management studies can contribute?”, Social Science Computer Review, Vol. 24 No. 3, pp. 310-325.

Nadeem, S. (2009), "Macaulay's (cyber) children: the cultural politics of outsourcing in India", Cultural Sociology, Vol. 3 No. 1, pp. 102-122.

Noronha, E. and D'Cruz, P. (2006), “Organising call Centre agents: emerging issues”, Economic and Political Weekly, Vol. 41 No. 21, pp. 2115-2121.

Nundy, S. and Gulhati, C.M. (2005), "A new colonialism? Conducting clinical trials in India", New England Journal of Medicine, Vol. 352 No. 16, pp. 1633-1666.

Ofreneo, R., Ng, C. and Marasigan-Pasumbal, L. (2007), "Voice for the voice workers: addressing the IR concerns in the call center/BPO industry of Asia”, Indian Journal of Industrial Relations, Vol. 42 No. 4, pp. 534-557.

Orlikowski, W.J. and Baroudi, J.J. (1991), "Studying information technology in organizations: research approaches and assumptions", Information Systems Research, Vol. 2 No. 1, pp. 1-28.

Papanastassiou, M., Pearce, R. and Zanfei, A. (2020), "Changing perspectives on the internationalization of R\&D and innovation by multinational enterprises: a review of the literature", Journal of International Business Studies, Vol. 51 No. 4, pp. 623-664.

Petryna, A. (2009), When Experiments Travel. Clinical Trials and the Global Search for Human Subjects, Princeton University Press, Princeton.

Phillip, K. (2016), "Telling histories of the future: the imaginaries of Indian technoscience”, Identities, Vol. 23 No. 3, pp. 276-293.

Phillip, K., Irani, L. and Dourish, P. (2012), "Postcolonial computing: a tactical survey", Science, Technology, \& Human Values, Vol. 37 No. 1, pp. 3-29. 
Poster, W.R. (2007), "Who's on the line? Indian call center agents pose as Americans for U.S.outsourced firms", Industrial Relations, Vol. 46 No. 2, pp. 271-304.

Poster, W.R. (2011), "Emotion detectors, answering machines and e-unions: multi-surveillances in the global interactive service industry", American Behavioral Scientist, Vol. 55 No. 7, pp. 868-901.

Prasad, A. (2009), "Capitalizing disease: biopolitics of drug trials in India”, Theory, Culture and Society, Vol. 26 No. 5, pp. 1-29.

Radhakrishnan, S. (2007), "Rethinking knowledge for development: transnational knowledge professionals and the 'new' India", Theory and Society, Vol. 36 No. 2, pp. 141-159.

Rao, P.M. (2008), "The emergence of the pharmaceutical industry in the developing world and its implications for multinational enterprise strategies", International Journal of Pharmaceutical and Healthcare Marketing, Vol. 2 No. 2, pp. 103-116.

Ravishankar, M.N., Shan, L. and Myers, M.D. (2013), "Information technology offshoring in India: a postcolonial perspective", European Journal of Information Systems, Vol. 22 No. 4, pp. 387-402.

Richardson, H. and Howcroft, D. (2006), "The contradictions of CRM - a critical lens on call centers", Information and Organization, Vol. 16, pp. 56-81.

Riggins, F.J. and Mukhopadhyay, T. (1994), "Interdependent benefits from interorganizational systems: opportunities for business partner reengineering", Journal of Management Information Systems, Vol. 11 No. 2, pp. 37-57.

Russell, B. (2007), "You gotta lie to it': software applications and the management of technological change in a call Centre", New Technology, Work and Employment, Vol. 22 No. 2, pp. 132-145.

Russell, B. (2008), "Call centres: a decade of research”, International Journal of Management Reviews, Vol. 10 No. 3, pp. 195-219.

Sariola, S., Ravindran, D., Kumar, A. and Jeffery, R. (2015), "Big-pharmaceuticalisation: clinical trials and contract research organisations in India", Social Science and Medicine, Vol. 131, pp. 239-246.

Sartor, M. and Beamish, P. (2014), "Offshoring innovation to emerging markets: organizational control and informal institutional distance", Journal of International Business Studies, Vol. 45 No. 9, pp. 1072-1095.

Siddiqui, S., Sharma, S., Sharma, B. and Siddiqui, A.A. (2010), "Role of serendipity in drug discovery", Journal of Pharmaceutical Research, Vol. 9 No. 2, pp. 49-55.

Stahl, B.C. and Brooke, C. (2008), "The contribution of critical is research", Communications of the $A C M$, Vol. 51 No. 3, pp. 51-55.

Steadman, A.V. (2018), "Drug discovery: Collaborations between contract research organizations and the pharmaceutical industry", ACS Medicinal Chemistry Letters, Vol. 9 No. 7, pp. 581-583.

Studt, T. (2004), "LIMS ready to break out", R\&D magazine, June, available at: www.rdmag.com

Subramaniam, S. and Dugar, S. (2012), "Outsourcing drug discovery to India and China: from surviving to thriving”, Drug Discovery Today, Vol. 17 Nos 19/20, pp. 1055-1058.

Sunder Rajan, K. (2006), Biocapital: The Constitution of Postgenomic Life, Duke University Press, Durham.

Taylor, P. and Bain, P. (1999), "An assembly line in the head': work and employee relations in the call Centre”, Industrial Relations Journal, Vol. 30 No. 2, pp. 101-117.

Taylor, P. and Bain, P. (2001), "Trade unions, workers' rights and the frontier of control in UK call centres", Economic and Industrial Democracy, Vol. 22 No. 1, pp. 39-66.

Taylor, P. and Bain, P. (2005), "India calling to the far away towns': the call centre labour process and globalization", Work, Employment and Society, Vol. 19 No. 2, pp. 261-282.

Trusson, C., Hislop, D. and Doherty, N.F. (2018), "The role of ICTs in the servitisation and degradation of IT professional work", New Technology, Work and Employment, Vol. 22 No. 2, pp. 149-170. 
CPOIB 18,3

UNCTAD (2005), World Investment Report 2005, Transnational corporations and the internationalization of R\&D, United Nations, New York, NY.

Upadhya, C. (2007), "Employment, exclusion and 'merit' in the Indian IT industry", Economic and Political Weekly, Vol. 42 No. 20, pp. 1863-1868.

Valle, M.A., Varas, S. and Ruz, G.A. (2012), "Job performance prediction in a call center using a naive Bayes classifier", Expert Systems with Applications, Vol. 39 No. 11, pp. 9939-9945.

Vora, K. (2013), Life Support: biocapital and the New History of Outsourced Labor, University of MN, $\mathrm{MN}$.

Whelan, K.E. and King, R.D. (2004), "Intelligent software for laboratory automation”, Trends in Biotechnology, Vol. 22 No. 9, pp. 440-445.

Zimmermann, A. (2011), "Interpersonal relationships in transnational, virtual teams - towards a configurational perspective", International Journal of Management Reviews, Vol. 13 No. 1, pp. 59-78.

Zuboff, S. (1988), In the Age of the Smart Machine, Heineman, Oxford.

\section{Further reading}

www.marketresearchfuture.com/Report Code: MRFR/Pharma/2151-HCR

Fda.gov (2021), “CFR 21 part 11 regulation”, available at: https://www.fda.gov/regulatory-information/ search-fda-guidance-documents/part-11-electronic-records-electronic-signatures-scope-andapplication

Kavita, P. (2016), "Telling histories of the future: the imaginaries of Indian technoscience", Identities, Vol. 23 No. 3, pp. $276-293$.

Philip, K., Irani, L. and Dourish, P. (2012), "Postcolonial computing: a tactical survey", Science, Technology and Human Values, Vol. 37 No. 1, pp. 3-29.

Sunder Rajan, K. (2005), "Subjects of speculation: emergent life sciences and market logics in the United States and India", American Anthropologist, Vol. 107 No. 1, pp. 19-30.

Sunder Rajan, K. (2011), "Property, rights and the constitution of Indian biomedicine: notes from the gleevec case", Social Research, Vol. 78 No. 3, pp. 975-998.

Taylor, P. and Bain, P. (2006), "Work organization and employee relations in Indian call centres", in Burgess, J. and Connell, J. (Eds), Developments in the Call Centre Industry, Routledge, London, pp. 36-57.

Taylor, P. and Bain, P. (2007), "Reflections on the call centre - a reply to Glucksmann", Work, Employment and Society, Vol. 21 No. 2, pp. 349-362.

Taylor, P., Mulvey, G., Hyman, J. and Bain, P. (2002), "Work organisation, control and the experience of work in call centres", Work, Employment and Society, Vol. 16 No. 1, pp. 133-150.

\section{Corresponding author}

Henrik Agndal can be contacted at: henrik.agndal@gu.se

For instructions on how to order reprints of this article, please visit our website: 